\title{
Testing facility for hydrogen storage materials designed to simulate application based conditions
}

\author{
R. J. Westerwaal, ${ }^{1, a)}$ R. G. Nyqvist, ${ }^{2}$ and W. G. Haije ${ }^{1,2}$ \\ ${ }^{1}$ Department of Chemical Engineering, Materials for Energy Conversion and Storage, Delft University of \\ Technology, Julianaweg 136, 2628 BL Delft, The Netherlands \\ ${ }^{2}$ Energy Research Centre of The Netherlands, Westerduinweg 3, 1755 LE Petten, The Netherlands
}

(Received 1 January 2011; accepted 7 March 2011; published online 19 April 2011)

\begin{abstract}
For the daily use of hydrogen storage materials, not only their intrinsic storage properties are important, but also equally important is the performance under practical conditions. Besides the techniques already available for the fundamental characterization of storage materials, there is a growing need to test storage materials under conditions resembling day-to-day use. For that we developed and tested a downscaled hydrogen storage reactor with which it is possible to monitor the hydrogenation behavior under nonideal conditions. Here we present a characterization of the developed reactor setup which enables a fast screening of storage materials. For characterization and calibration purposes, we use the rather well-documented $\mathrm{LaNi}_{5}-\mathrm{Al}$ alloy as reference. The found experimental results agree well with the properties of $\mathrm{LaNi}_{5}-\mathrm{Al}$ as reported in literature. Our results show that this reactor setup enables an efficient screening of new developed storage alloys under realistic conditions and is therefore complementary to the already existing characterization setups. () 2011 American Institute of Physics. [doi:10.1063/1.3571302]
\end{abstract}

\section{INTRODUCTION}

The increasing demand for clean energy has resulted in a worldwide interest in hydrogen as energy carrier as a potential long term solution to the growing energy use. It is expected that the global energy consumption will nearly double at 2050 which will put the production and use of fossil fuels under enormous pressure. Therefore to establish the transition toward a sustainable hydrogen based economy, the numerous scientific and technological hurdles must be unambiguously overcome between the current state of hydrogen production, infrastructure, utilization and storage, and those required for an actual day-to-day use. A key role in the transition toward a sustainable hydrogen based society is the efficient storage of hydrogen. Moreover, on-board hydrogen storage for mobile applications is a focal point of attention due to the zero emission prospects beneficial to especially the cities' air quality.

Under ambient conditions, hydrogen gas has a low density and therefore storage in high pressure cylinders, as a cryogenic liquid, or physisorbed/chemisorbed in solids is required. ${ }^{1}$ Solid sorbents, especially metal hydrides, are attractive candidates as they are intrinsically safe and allow for a very high volumetric storage capacity. However, hydrogen storage by means of metal hydrides faces huge challenges in the transition from laboratory research scale to actual applications.

To that the U.S. Department of Energy (DOE) has established, in the framework of the DOE Hydrogen Program, technological targets for the development of an efficient onboard hydrogen storage tank. For 2015, the aim is at a system gravimetric storage capacity of $5.5 \mathrm{wt}$. \% with a corresponding filling time of $\sim 3.3 \mathrm{~min}$ for $5 \mathrm{~kg} \mathrm{H}_{2}$. Besides the storage

\footnotetext{
a) Author to whom correspondence should be addressed. Electronic mail: ruudwesterwaal@hetnet.nl.
}

capacity, the heat development in the metal hydride during hydrogenation requires special attention. For example, filling a tank under these conditions, with an enthalpy of formation of $35 \mathrm{~kJ} / \mathrm{mol} \mathrm{H}_{2}$, results in a heat release of $\sim 450 \mathrm{~kW} .^{2}$ Depending on kinetics, thermodynamics, and heat transfer in the metal hydride bed, this will pose strong requirements on the heat management of the storage tank.$^{3-6}$ Heat and mass transfer through a hydride bed is a complex phenomenon where many possible mechanisms of heat transfer, viz., conduction, convection, and radiation are involved. So far many studies have been performed which aimed at understanding and optimizing metal hydride storage tanks by numerical models including studies on the heat and mass transfer processes in the metal hydride. These studies range from one-dimensional models with conduction, conduction plus convection, convection plus radiation, to two-dimensional and three-dimensional. ${ }^{4,7-18}$ Some of these numerical studies are accompanied by experimental investigations for validating the developed models directly ${ }^{19-29}$ as well as determining the hydrogenation characteristics of the metal hydrides ${ }^{30-36}$ and in addition empirical relations on effective thermal conductivity are obtained from experimental work. ${ }^{30,31,34,37,38}$

However, relatively little work has been done on the design and development of a realistic (downscaled) hydrogen storage tank or reactor to make the step from laboratory scale to applications for daily use. ${ }^{39}$ Furthermore, for any application, only a high storage capacity is not enough and issues such as ab(de)sorption rate, chemical/mechanical stability, poisoning, heat and mass transport under realistic and cyclic conditions, and last but not least upscaling of the metal hydride synthesis method are equally important.

In this paper, the design and development of a hydrogen storage reactor are described with which it is possible to characterize and study the hydrogenation behavior of a metal hydride bed under loading conditions characteristic for 
possible applications. This reactor setup is unique as it enables one to test the influence of the heat and mass flow, temperature effects, flow or "dead-end" reactor loading, bed stability, storage capacity, filling times, grain size, and contamination effects, simultaneously. To illustrate the performance, we use the rather well-documented $\mathrm{LaNi}_{5}-\mathrm{Al}$ compound as reference and calibration. ${ }^{40-44}$ Although the experiments are nonequilibrium measurements, the results are comparable to classical pressure composition temperature (PCT) measurements. The aim of this paper is on setup development and characterization and thereby addressing the topics indicated below. Furthermore, based on our findings, practical storage systems are discussed and the performance of this reactor will be compared to other (conventional) characterization techniques used for sorption research, i.e., Sieverts and thermally programmed desorption (TPD)-like setups.

Topics:

- Calibration, correction, standardization factors.

- Influence of feed flow.

- Temperature profiles.

- Pressure effects.

- Heat development/management.

- Enthalpy and entropy of hydride formation.

\section{METHODOLOGY}

\section{A. Reactor design}

The aim is to design and develop a hydrogen storage reactor with which it is possible to characterize newly developed storage materials over a broad range of hydrogenation conditions relevant for practical applications. Based on literature data concerning hydrogenation kinetics, thermodynamics, a storage capacity of up to $7.6 \mathrm{wt} . \%\left(\mathrm{MgH}_{2}\right)$, and a filling time of $1800 \mathrm{~s}$, we estimated the mass flows and heat management required for filling a metal hydride reactor of $125 \mathrm{~cm}^{3}$ filled with a metal hydride bed. This results in the following reactor requirements:

- The reactor needs to be filled and emptied under welldefined clean conditions.

- Larger storage beds should be possible $\left(>100 \mathrm{~cm}^{3}\right)$.

- Well-controlled operating temperatures between room temperature and $350^{\circ} \mathrm{C}$ (including active heating and cooling).

- Pressure range from a few mbar up to 75 bar.

- A hydrogen feed flow between 0.3 (slow kinetics, low capacity) and 14 (fast kinetics, high capacity) Ln/min (Ln: normalized liter).

- Possibility to add gas impurities to the feed gas, such as $\mathrm{CO}, \mathrm{CO}_{2}$, and $\mathrm{CH}_{4}$, and also measure the vent gas concentration levels.

- Measure and control the temperature development at relevant positions in the setup, especially inside the reactor.

- By controlling and measuring all heat and mass flows to and from the reactor, it should be possible to determine the intrinsic storage capacity, absorption/

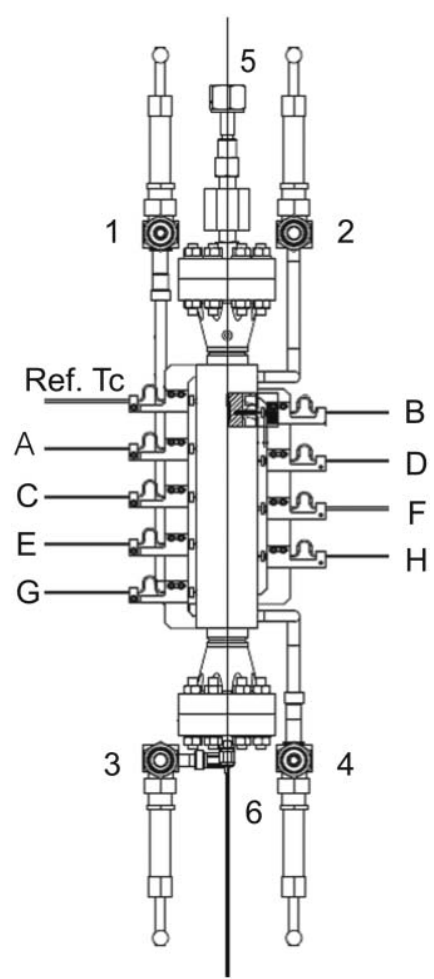

FIG. 1. Schematic representation of the reactor and the spacing of the different thermocouples A-H. (1) gas in, (2) oil out, (3) gas out, (4) oil out, (5) overpressure valve, and (6) heating wire.

desorption cycles, kinetic and thermodynamic effects, and the effect of gas impurities.

- Aimed filling times $<1800 \mathrm{~s}$.

\section{B. Reactor construction and specifications}

The metal hydride reactor is designed and developed with a reactor body of stainless steel (RVS AISI 316) and has an internal diameter of $2.5 \mathrm{~cm}$ and a height of $25 \mathrm{~cm}$, thus able to contain a reactor bed of $123 \mathrm{~cm}^{3}$. The reactor can be operated both in continuous flow and dead-end mode, see Fig. 1. The bed material used in this study is obtained from LabTech Int. Ltd. and is based on an $\mathrm{Al}$ doped $\mathrm{LaNi}_{5}$ compound.

Although the operating temperature and pressure range of the reactor allow for a wide range of metal hydrides to be tested, here $\mathrm{LaNi}_{5}-\mathrm{Al}$ is used because its hydrogenation characteristics are known and can be used for calibration purposes. ${ }^{40-44}$ Furthermore, it has a high absorption capacity, easy activation, moderate hysteresis, and fast hydriding and dehydriding rates. The used amount of $\mathrm{LaNi}_{5}-\mathrm{Al}$ is $161.27 \mathrm{~g}$ which results in a columnar bed of $9.5 \mathrm{~cm}$ high and $2.5 \mathrm{~cm}$ in diameter $\left(\sim 46.6 \mathrm{~cm}^{3}\right)$. Although this is a heavy metal hydride, it is recognized that this material has a wide range of practical applicability. ${ }^{39,45}$

The reactor is filled in an anaerobic dry glovebox (during filling $\mathrm{H}_{2} \mathrm{O}$ and $\mathrm{O}_{2}$ levels $<100 \mathrm{ppm}$ ) to prevent oxidation and contamination effects. The bed material is contained in the reactor by several micromesh filters (Sika-R 0,5). This allows hydrogen to flow freely through the filters to reach the storage material. A total of nine thermocouples with an 


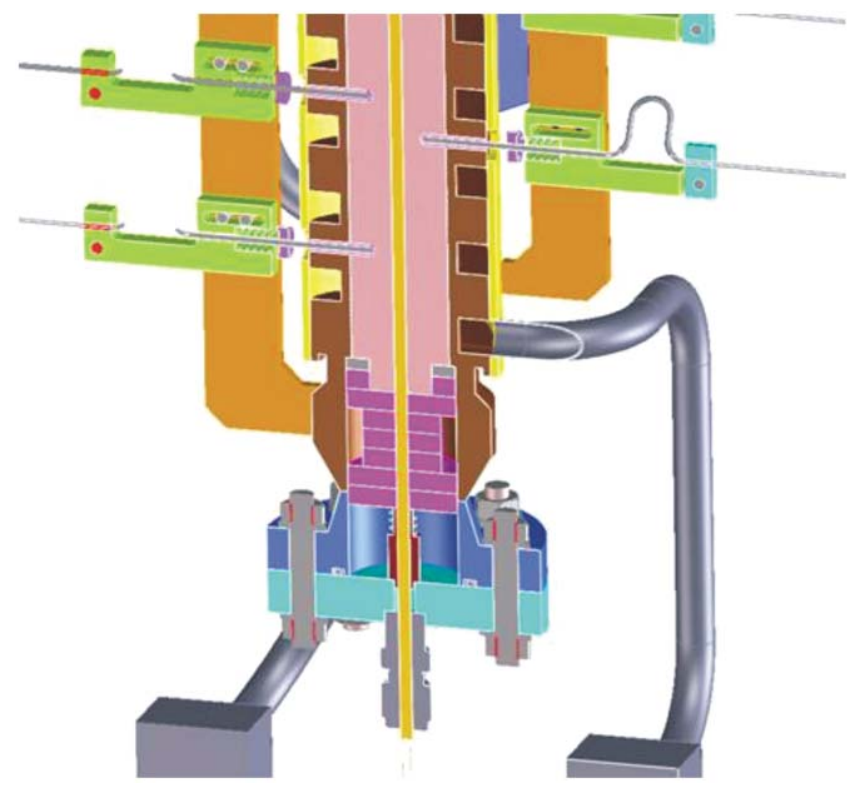

FIG. 2. (Color online) Schematic representation of the position of the thermocouples in the reactor making direct contact with the reactor bed.

accuracy of $\pm 1.0^{\circ} \mathrm{C}$ are arranged on both sides of the reactor and are placed inside the reactor bed, as shown in Fig. 2. The thermocouples are axially separated by 10,20 , and $30 \mathrm{~mm}$ alternating on both sides of the reactor, but the radial position is the same for all thermocouples.

In the reactor wall, a coil heat exchanger is constructed with a diameter of the flow-channel of $8 \mathrm{~mm}$. As heat exchanger fluid, we use MARLOTHERM ${ }^{\circledR}$ SH Heat Transfer Fluid, allowing operating temperatures between 30 and $350{ }^{\circ} \mathrm{C}$. The temperature of the heat exchanger fluid is controlled by a Julabo high temperature circulator HT30-M1 with C.U.-cooling unit, allowing for heating, cooling, and isothermal experimental conditions. The feed gas flow is in the opposite direction of the oil flow. A central heater inside the reactor can provide extra power during hydrogenation experiments if required. The reactor is sealed by flanges on the top and bottom which compress o-rings to ensure a proper seal from a few mbar up to 75 bar of hydrogen pressure. Safety controls prevent the reactor from being overheated and a pressure relief valve opens in case the pressure becomes too high. The influence of hydrogen contaminations can be investigated real time using a CompactGC, which can sample both the feed gas composition and the gas from the reactor bed during desorption.

A schematic representation of the experimental reactor setup is shown in Fig. 3. The metal hydride reactor is placed in an insulated housing and the gas and heat exchanger fluid inlet and outlet are connected using swagelock fittings. The setup enables hydrogen filling and emptying at a set temperature and gas flow rate. The whole reactor setup can be preflushed with nitrogen (purity $5 \mathrm{~N}$ ) and hydrogenated from a high pressure hydrogen cylinder (purity $5 \mathrm{~N}$ ). The feed flow can be heat traced if required and flows typically range from 0.274 to $13.7 \mathrm{Ln} / \mathrm{min}$. All heat and mass flows, to and from the reactor, are monitored by various flow controllers, thermocouples, and pressure gauges, which are connected to the

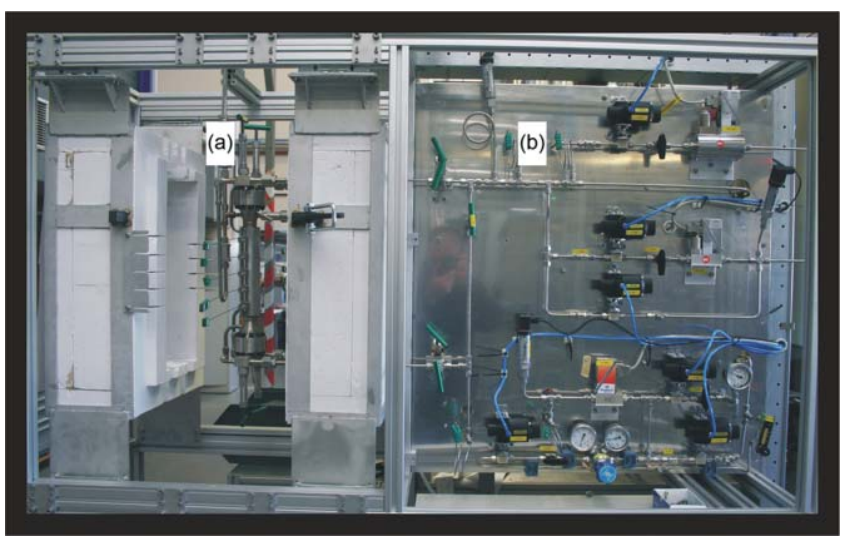

FIG. 3. (Color online) Schematic representation of the complete reactor setup. The left side (a) shows the reactor part and insulation, the right part (b) shows the gas handling system.

control and data acquisition system. The setup is designed in such a way that the reactor can be removed from the setup to handle the reactor bed inside a glovebox.

\section{EXPERIMENTAL PROCEDURE}

After placing the (filled) reactor, the whole setup is flushed with $\mathrm{N}_{2}$ and subsequently pumped vacuum. Once the reactor reached the set temperature, hydrogenation experiments can be performed. All experiments described here are done in dead-end reactor configuration, however, hydrogenation experiments with a certain flow over the bed are also possible. To determine the dead-volume of the setup/reactor, empty reactor filling experiments are performed with both $\mathrm{N}_{2}$ and $\mathrm{H}_{2}$ at different temperatures and feed flows. In this way, a total setup volume of $390 \mathrm{~cm}^{3}$ (tubing, components, reactor, etc.) is determined. Since we are interested in application oriented filling times, the reactor can also be filled at feed flows exceeding the hydrogen uptake rate of the metal hydride (nonequilibrium conditions).

\section{A. Calibration and corrections}

The hydrogen storage capacity of the bed can be determined with three methods. First, the empty reactor volume is determined by filling it under well-defined conditions (flow, pressure $(\mathrm{P})$, and temperature $(\mathrm{T})$ ). With this obtained volume, the storage capacity is calculated by correcting for the volume not occupied by the storage material. With the second method, the storage capacity of the reactor bed is determined by filling the reactor with $\mathrm{N}_{2}$ and subsequently by $\mathrm{H}_{2}$ under identical conditions. The difference between the $\mathrm{N}_{2}$ and $\mathrm{H}_{2}$ loading curves is due to the hydrogen absorption by the reactor bed. Here, we use a third approach; the empty reactor is filled with a hydrogen flow at different conditions which are used as reference measurements, see Figs. 4 and 5. Furthermore, these empty reactor filling experiments show that no hydrogen is absorbed by the setup itself and for a constant feed flow, a steady and linear pressure increase is obtained. Furthermore, temperature has only a small influence on the pressure-time development of the empty reactor. 


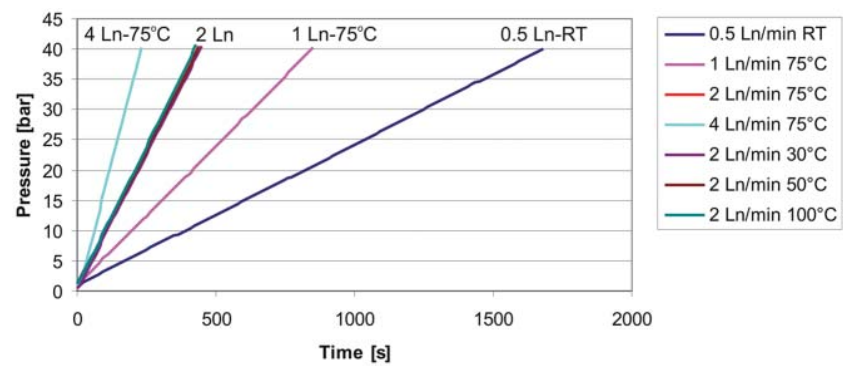

FIG. 4. (Color online) Empty reactor $\mathrm{H}_{2}$ filling experiments at different feed flows and temperatures showing a linear pressure increase.

\section{B. Enthalpy of formation}

By measuring the pressure development as function of feed time ( $\sim$ the amount of hydrogen added to the reactor), pressure-capacity-temperature (PCT) isotherms can be constructed which are qualitatively analogous to "classical" pressure composition isotherms (PCT) obtained with standard volumetric or gravimetric methods.

The $\Delta S_{0}$ and $\Delta H$ of the hydrogen absorption processes are determined from the temperature dependence of the plateau pressures in the PCTs according to the Van 't Hoff relation, ${ }^{46}$

$$
\ln \left(\frac{p}{p_{0}}\right)=\frac{\Delta H}{R T}-\frac{\Delta S_{0}}{R},
$$

with $\Delta H$ the enthalpy of formation in $\mathrm{J}\left(\mathrm{mol} \mathrm{H}_{2}\right)^{-1}, \Delta S_{0}$ is the entropy of formation in $\mathrm{J} \mathrm{K}^{-1}\left(\mathrm{~mol} \mathrm{H}_{2}\right)^{-1}$ at standard pressure $p_{0}=1.013 \times 10^{5} \mathrm{~Pa}, R$ is the gas constant, $T$ is the absolute temperature, and $p$ is the $\mathrm{H}_{2}$ equilibrium plateau pressure of the PCTs. If, in a first approximation, $\Delta S_{0}$ is mainly determined by the loss of entropy when gaseous $\mathrm{H}_{2}$ is absorbed by the metal hydride, i.e., $\Delta S_{0} \sim-\Delta S_{\mathrm{H}_{2}}$ $=-130.684 \mathrm{~J}\left(\mathrm{~K} \mathrm{~mol} \mathrm{H}_{2}\right)^{-1}$ at $10^{5} \mathrm{~Pa}$ and room temperature, then hydrogen storage material for practical applications will have an enthalpy of formation which is in the order of $-40 \mathrm{~kJ}\left(\mathrm{~mol} \mathrm{H}_{2}\right)^{-1} .47$ This implies that any application which operates at a hydrogen feed pressure of 1 bar at room temperature has to control an enthalpy of formation of around $40 \mathrm{~kJ}$ per $\sim 2 \mathrm{~g}$ of stored hydrogen.

\section{RESULTS AND DISCUSSION}

The hydrogenation behavior of a reactor filled with a $\mathrm{LaNi}_{5}-\mathrm{Al}$ bed is shown in Fig. 6 for the first four hydrogenation cycles. The applied hydrogen pressure is plotted (up to $40 \mathrm{bar}$ ) versus loading time at a $\mathrm{H}_{2}$ feed flow of $0.5 \mathrm{Ln} / \mathrm{min}$ and a reactor set temperature of $30^{\circ} \mathrm{C}$. Figure 7 shows the hydrogen storage capacity (in $\mathrm{mol} \mathrm{H}_{2}$ ) of the reactor bed as a function of hydrogen pressure. In both figures also the hydrogen filling of an empty reactor at $0.5 \mathrm{Ln} / \mathrm{min}$ and $23^{\circ} \mathrm{C}$ is shown as a reference. The first hydrogenation cycle shows an interesting feature. Although it is obvious from loadings 2, 3 , and 4 that the $\mathrm{LaNi}_{5}-\mathrm{Al}$ bed absorbs hydrogen readily at low hydrogen pressures, the first hydrogenation cycle shows no hydrogen uptake up to 29.6 bar. The pressure development follows the empty reactor filling characteristics up to $29.6 \mathrm{bar}$ after which a sudden pressure decrease occurs. The metal hydride starts to absorb hydrogen and this hydrogen uptake rate is higher than the hydrogen feed flow, resulting in a pressure decrease. After the bed is saturated (at around $2800 \mathrm{~s}$ ), the pressure increases again at a rate comparable to that of filling an empty reactor. In contrast to the first hydrogenation cycle, the second, third, and fourth cycles do not show this "activation" barrier and the cycles are comparable. The observed activation barrier is most probably related to hydrogen embrittlement, a restructuring of the microstructure of the metal hydride and a surface oxide layer. Hydrogen embrittlement plays an important role, as the reactor bed may pulverize upon repeated cycling (as is the case for the $\mathrm{LaNi}_{5}$ based compounds). This may result in a more dense bed and thereby increasing the pressure drop over the bed, change the stress distribution and heat transfer through the bed. For hydrogen embrittlement different mechanisms are proposed such as the formation of high pressure bubbles ${ }^{48}$ a reduction in surface energy, ${ }^{49}$ a reduction in the lattice cohesive force, ${ }^{50}$ hydrogen interaction with dislocations, ${ }^{51-55}$ and hydride formation. ${ }^{56,57}$ The time required for a full hydrogenation of the reactor bed

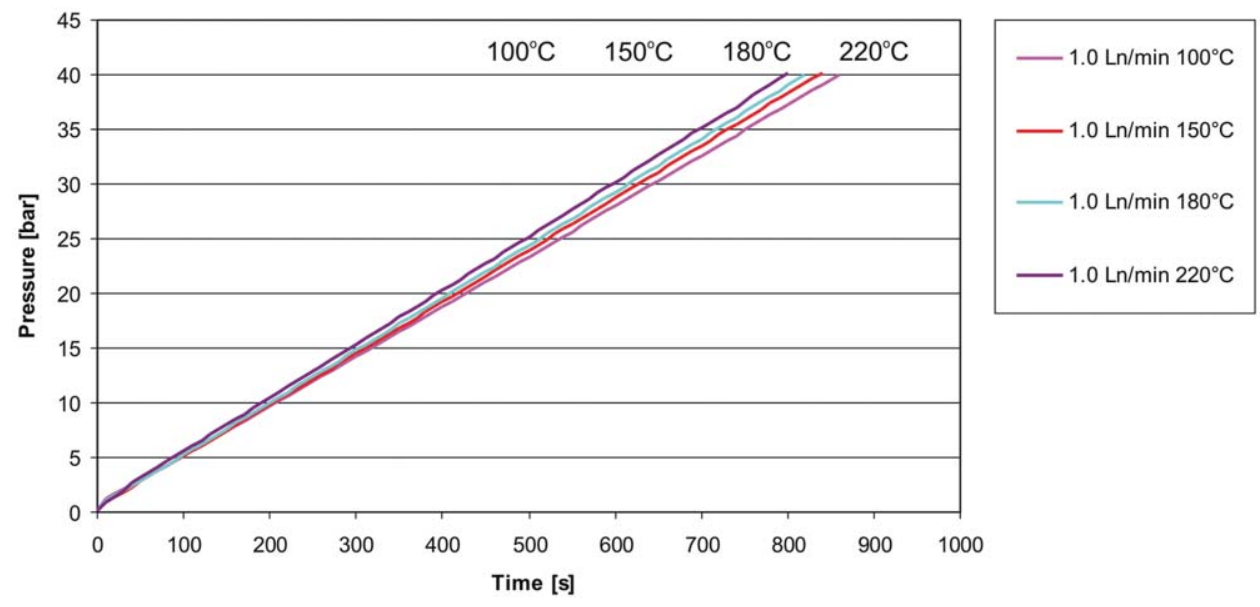

FIG. 5. (Color online) Empty reactor filling experiments for different temperatures at a constant hydrogen feed flow of $1.0 \mathrm{Ln} / \mathrm{min}$ showing a linear increase in pressure. The reduced filling time ( $=$ capacity) as function of increasing temperature is as expected for the storage capacity of the reactor. 

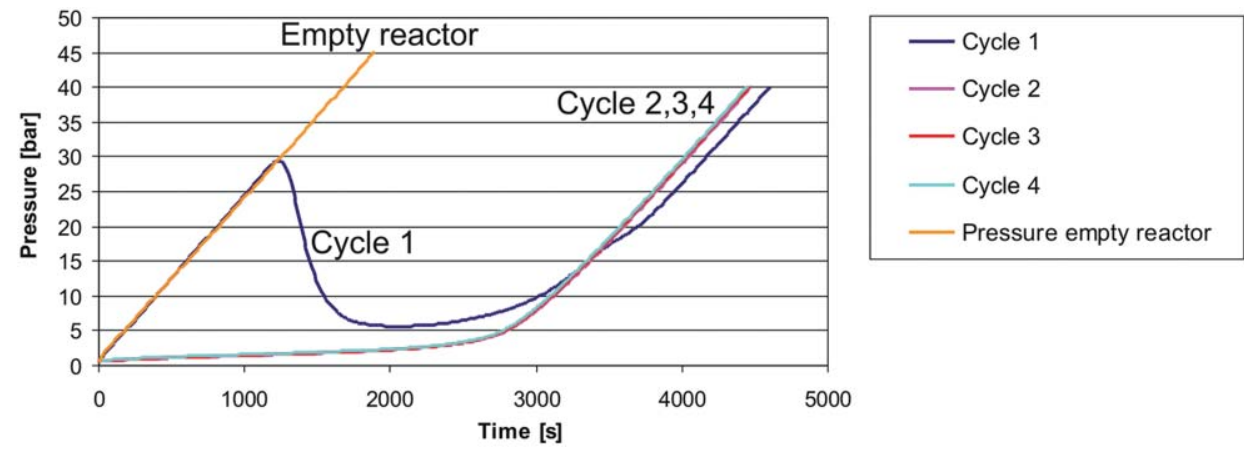

FIG. 6. (Color online) The first four consecutive hydrogen absorption isotherms at $30^{\circ} \mathrm{C}$ for a $\mathrm{LaNi}_{5}-\mathrm{Al}$ bed with a hydrogen feed flow of $0.5 \mathrm{Ln} / \mathrm{min}$. For comparison an empty reactor $\mathrm{H}_{2}$ filling at a flow $0.5 \mathrm{Ln} / \mathrm{min}$ at $23^{\circ} \mathrm{C}$ is also shown.

is obvious from the change in slope of the hydrogenation isotherms (around $3000 \mathrm{~s}$ ). The storage capacity of the reactor bed is determined from the difference between the capacity of the empty and filled reactor, which for a reactor filled with $161.27 \mathrm{~g} \mathrm{LaNi}_{5}-\mathrm{Al}$, results in $1.06 \mathrm{~mol} \mathrm{H}_{2}$ and corresponds to a gravimetric storage capacity of $1.36 \mathrm{wt}$ \%, in agreement with literature data. ${ }^{40-44}$

\section{A. Pressure capacity temperature isotherms}

The isothermal hydrogenation measurements of the reactor bed are a key element in determining the material performance for any hydrogen storage application. By measuring the hydrogen pressure as a function of filling time at a set feed flow, we are able to construct pressure-capacity-temperature isotherms. Figures 8 and 9 show typical hydrogen loadings at feed flows 0.5 and $1.0 \mathrm{Ln} / \mathrm{min}$ (nonequilibrium) in the temperature range $30-170^{\circ} \mathrm{C}$ up to a hydrogen pressure of 40 bar both as a function of time and capacity. The pressure development of the isotherms shows a hydrogenation behavior which is comparable to standard PCT isotherms obtained with Sieverts' like methods. ${ }^{58}$ At the start, the slow pressure increase with time corresponds to the plateau pressure of the two phase region of the metal hydride bed. The plateaus resulting from the coexistence of the $\alpha$ and $\beta$ phases show a slope, which is most likely due to a combination of stress development and nonequilibrium filling effects. The width of the plateaus reduces (and the slope increases) as a function of increasing temperature indicating the proximity of the critical temperature. As a result, the storage capacity of the reactor bed also decreases strongly with increasing temperature from 1.36 wt. $\%$ at $30^{\circ} \mathrm{C}$ to $\sim 0.39$ wt. $\%$ at $170{ }^{\circ} \mathrm{C}$, see Fig. 10 where the storage capacity of the $\mathrm{LaNi}_{5}-\mathrm{Al}$ bed is plotted as a function of temperature. The storage capacity of the $\mathrm{LaNi}_{5}-\mathrm{Al}$ bed is determined by the storage difference between the empty and the reactor filled with a bed. The reduction of storage capacity at increasing temperature is an important issue as certain applications can only operate at higher temperatures and thereby require a storage bed at a comparable temperature to be functional and efficient.

From the pressure capacity isotherms we are able to construct Van 't Hoff plots by determining the pressure at the middle of the plateau region during hydrogen absorption. The Van 't Hoff plots of the plateau pressures are remarkably linear, see Fig. 11. For a feed flow of $0.5 \mathrm{Ln} / \mathrm{min}$, an enthalpy and entropy of formation of $\Delta H=-23539.9 \mathrm{~J}\left(\mathrm{~mol} \mathrm{H}_{2}\right)^{-1}$ and $\Delta S$ $=-80.95 \mathrm{~J}\left(\mathrm{~K} \mathrm{~mol} \mathrm{H}_{2}\right)^{-1}$ are found, while for a feed flow of $1.0 \mathrm{Ln} / \mathrm{min} \Delta H=-22536.4 \mathrm{~J}\left(\mathrm{~mol} \mathrm{H}_{2}\right)^{-1}$ and $\Delta S=-80.12$ $\mathrm{J}(\mathrm{K} \mathrm{mol} \mathrm{H})^{-1}$ are found. Thus a higher feed flow merely results in a shift to higher pressures but does not influence the slope $(\Delta H)$. These values underestimate the ones reported in literature ( $\sim 30 \mathrm{~kJ} \mathrm{H}_{2}{ }^{-1}$ for $\mathrm{LaNi}_{5}$; Refs. 59, 60, and 61), which is most likely caused by the set temperature of the reactor heat exchanger, the actual bed temperature development during hydrogen absorption and the contact between the bed material and the thermocouple. Part of future work will be aimed at optimizing, scaling, and correcting these effects.

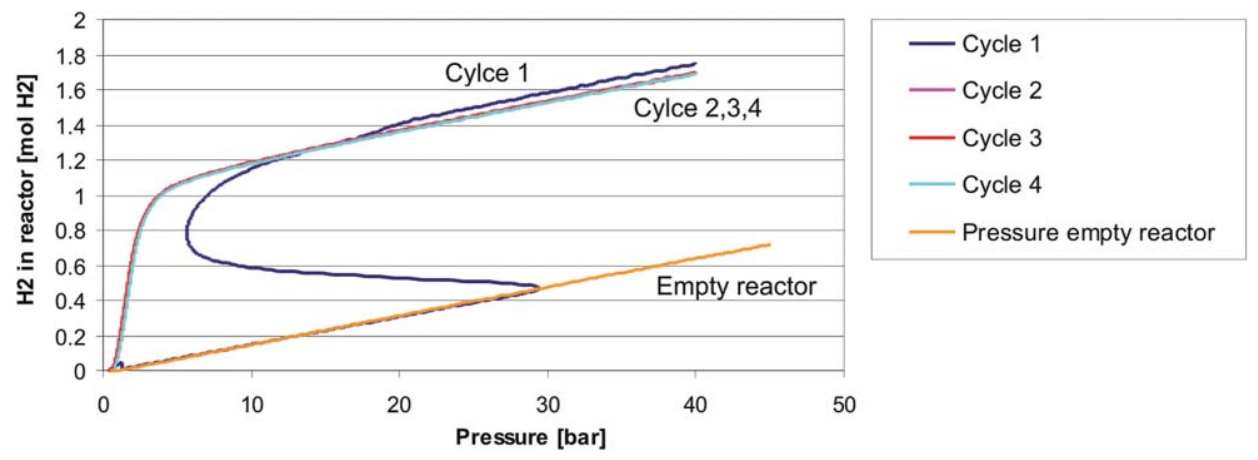

FIG. 7. (Color online) The hydrogen storage capacity of the reactor and bed for the first four consecutive hydrogen absorption isotherms at $30^{\circ} \mathrm{C}$. From the empty reactor filling measurement an empty volume of $390 \mathrm{~cm}^{3}$ is determined. 


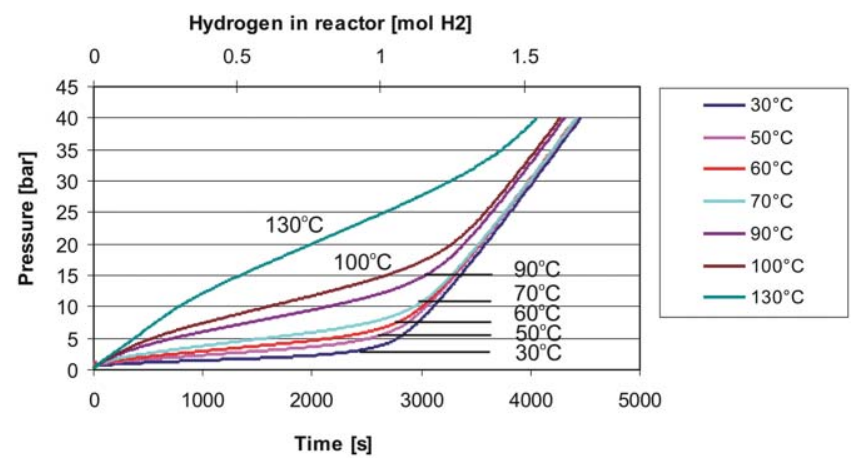

FIG. 8. (Color online) Hydrogen reactor loadings as function of time and hydrogen capacity of the reactor at a feed flow of $0.5 \mathrm{Ln} / \mathrm{min}$ at temperatures between 30 and $170^{\circ} \mathrm{C}$ up to a maximum pressure of 40 bar.

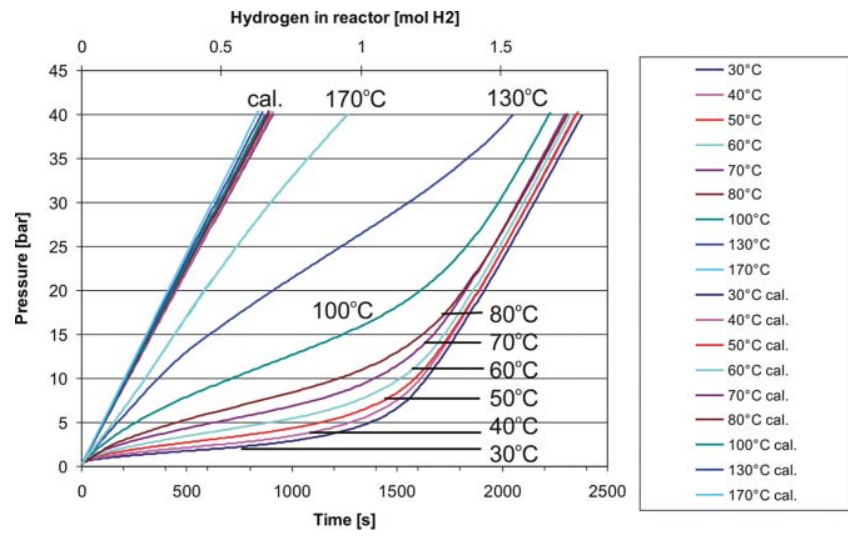

FIG. 9. (Color online) Hydrogen reactor loadings at a feed flow of $1 \mathrm{Ln} / \mathrm{min}$ at temperatures between 30 and $170^{\circ} \mathrm{C}$ up to a maximum pressure of $40 \mathrm{bar}$. For comparison also the fillings of an empty reactor (indicated by cal.) are shown.

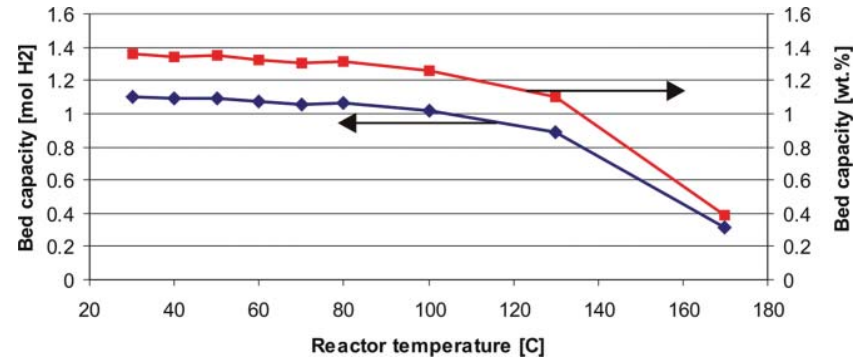

FIG. 10. (Color online) Hydrogen storage capacities as function of temperature at a feed flow of $1 \mathrm{Ln} / \mathrm{min}$. On the left y axis the storage capacity of the $\mathrm{LaNi}_{5}-\mathrm{Al}$ bed in number of mol and on the right $\mathrm{y}$ axis the storage capacity in wt. $\%$ are plotted.

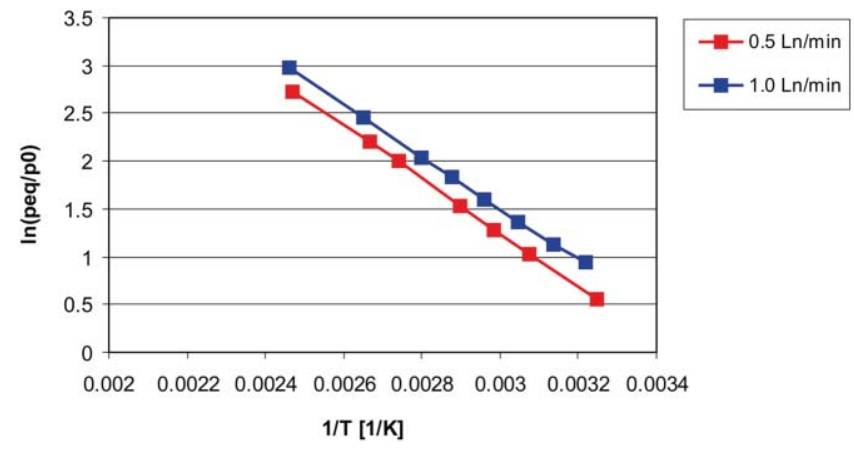

FIG. 11. (Color online) The determined temperature dependence of the plateau pressure (Van 't Hoff plot) during hydrogen absorption $(\alpha \rightarrow \beta)$ for a $\mathrm{LaNi}_{5}-\mathrm{Al}$ reactor bed at hydrogen fill flows of 0.5 and $1.0 \mathrm{Ln} / \mathrm{min}$.

\section{B. Heat development}

The heat development inside the reactor depends strongly on the hydrogen feed flow, set temperature, kinetics, and thermodynamics of the used bed. ${ }^{40}$ For storage applications, the filling time is an important property and thus so is the heat management. To determine how the heat development in the reactor is influenced by the different process parameters, we first examine the hydrogen absorption as a function of feed flow at a set temperature of $50^{\circ} \mathrm{C}$, see Fig. 12. Due to fast absorption kinetics, the hydrogen pressure only slightly increases at a feed flow of $0.5 \mathrm{Ln} / \mathrm{min}$ until the metal bed is saturated after which a steep increase in pressure follows. At this feed flow and set temperature, the bed is filled in about $2800 \mathrm{~s}$ with a local bed temperature increase of only $2{ }^{\circ} \mathrm{C}$. At higher feed flows of 1.0 and $3.5 \mathrm{Ln} / \mathrm{min}$ the bed temperature increases by 5 and $17^{\circ} \mathrm{C}$, respectively, whereas the filling time reduces to $700 \mathrm{~s}$ at $3.5 \mathrm{Ln} / \mathrm{min}$. The point where the temperature changes from increasing to decreasing corresponds to a fully hydrogenated reactor bed. Furthermore, at high feed flows the bed is not yet saturated at 40 bar and when the feed flow stops the pressure decreases slightly. Furthermore, the hydrogen absorption process at higher feed flows is hindered by this extra temperature increase as the exothermic hydrogen absorption reaction rate is more favorable at lower temperatures.

The axial temperature evolution of the bed is in shown in Fig. 13 for a feed flow of $3.5 \mathrm{Ln} / \mathrm{min}$ at a set temperature of $50^{\circ} \mathrm{C}$. Also the pressure development inside the reactor is plotted for clarity. At this high feed flow, the system is no longer under isothermal conditions and the local temperature of the bed increases strongly as pointed out by thermocouples $\mathrm{G}$ and $\mathrm{H}$. The thermocouples $\mathrm{G}$ and $\mathrm{H}$ are in the bed whereas thermocouple $\mathrm{E}$ is just at the top of the bed, which explains the sudden change in temperature measured by thermocouple E. The small increase in temperature indicated by the other thermocouples is caused by the heat exchanger oil passing by. The local bed temperature reaches a maximum of about $66^{\circ} \mathrm{C}$ after which the temperature decreases again when the absorption rate of the bed slows down.

The pressure drop over the reactor bed is related to the heat development and reactor filling time because it influences the filling rate of the reactor. Since the reactor specifications are known, we are in principle able to calculate the pressure drop over the reactor bed by using the Ergun equation. However, there is a strong dependence on the specific bed properties, such as grain size and form, which changes as function of cycling. ${ }^{62}$ Therefore, the pressure drop is measured over the reactor bed at a set temperature of $50^{\circ} \mathrm{C}$ for different feed flows of 0.5, 1.0, and 3.5 Ln/min, see Fig. 14. At the onset of the hydrogen feed flow $(t=0)$ a peak in the pressure drop over the bed is observed which is related to the switching of the flow controller. Thereafter the pressure drop decreases to almost constant values between 0.05-0.13 bar for all three feed flows. Furthermore, the pressure drop linearly increases with the length of the bed which needs to be considered in the construction of a real storage reactor since a long thin tubular reactor bed makes heat management more easy whereas a short and wide bed reduces the pressure drop. 

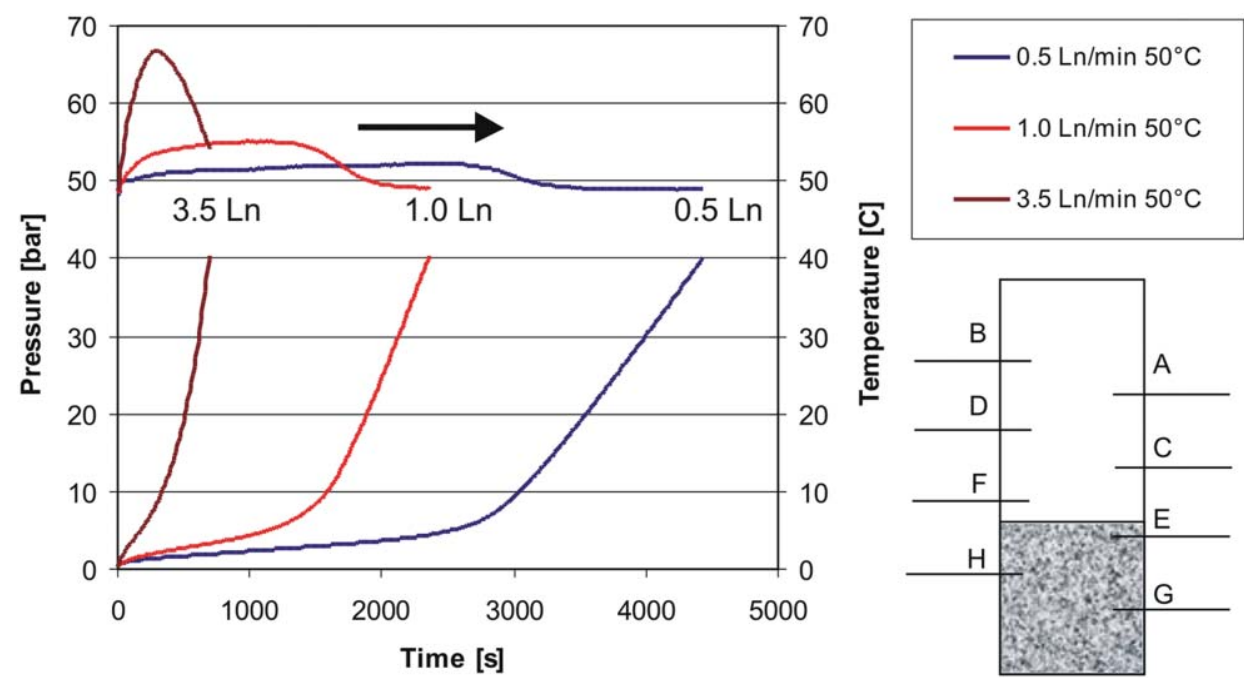

FIG. 12. (Color online) The reactor bed temperature (thermocouple $\mathrm{H}$, in the middle of the bed) at a set temperature of $50^{\circ} \mathrm{C}$ for hydrogen feed flows of 0.5 , 1.0 , and $3.5 \mathrm{Ln} / \mathrm{min}$. The position of the thermocouples are indicated in the insert. The inset shows the order of the thermocouples inside the reactor.

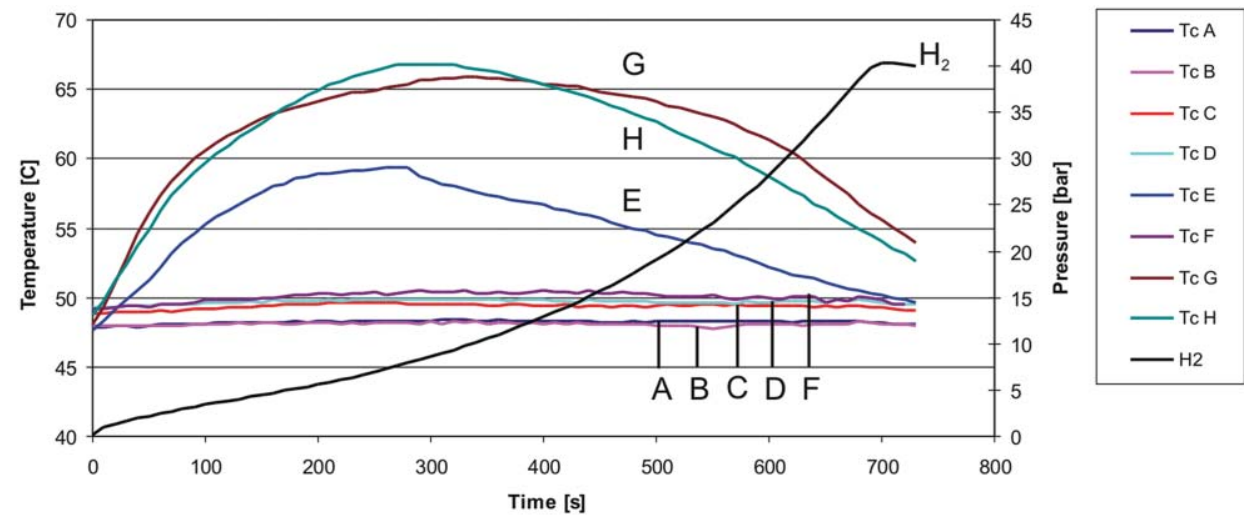

FIG. 13. (Color online) Axial reactor bed temperature at a heat-exchanger set temperature of $50^{\circ} \mathrm{C}$ for hydrogen feed flows of $3.5 \mathrm{Ln} / \mathrm{min}$.

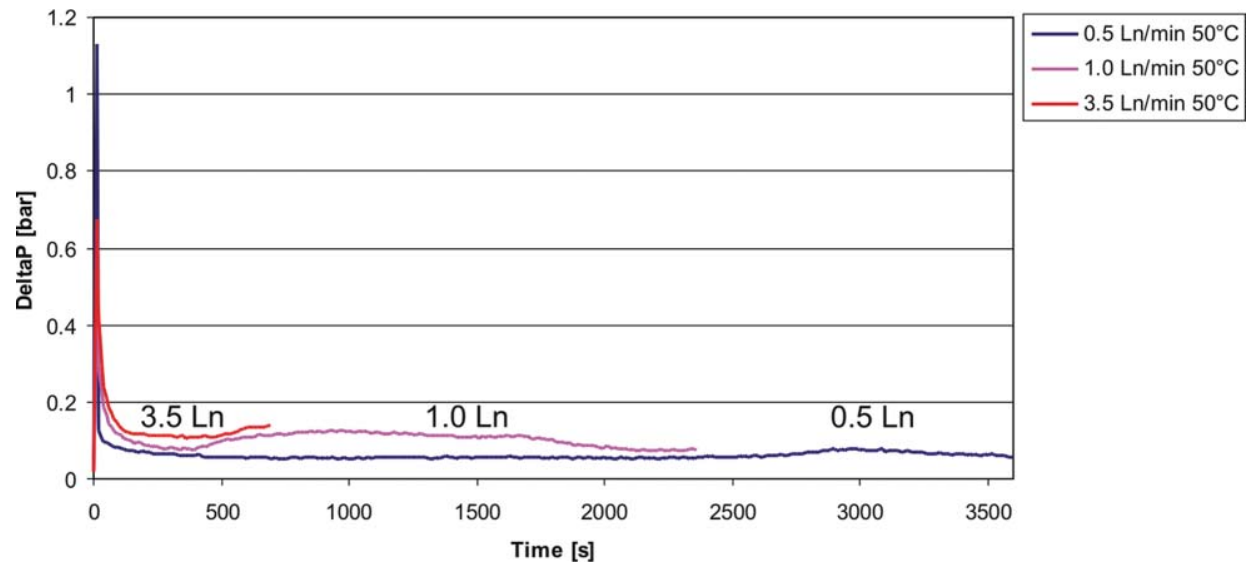

FIG. 14. (Color online) Pressure drop over the reactor bed at a set temperature of $50^{\circ} \mathrm{C}$ for hydrogen feed flows of $0.5,1.0$, and $3.5 \mathrm{Ln} / \mathrm{min}$. 


\section{DISCUSSION AND CONCLUSIONS}

In this paper, we demonstrated the functionalities of a newly designed and developed multipurpose metal hydride storage reactor capable of testing various novel developed metal hydrides. A typical $\mathrm{LaNi}_{5-x} \mathrm{Al}_{x}$ metal hydride bed is used for testing the functionalities of the setup. Reactor beds can be tested under various conditions of feed flow, temperature, pressure, and gas composition. It is possible to perform either measurements with a flow or dead-end reactor at isothermal conditions.

In addition, it is possible to determine the storage capacity of metal hydride bed in good agreement with literature values for bulk quantities of storage material within the temperature range from 25 to $350{ }^{\circ} \mathrm{C}$ at pressures up to 75 bar.

Furthermore, if the gas flow is not too high as compared to the hydrogen absorption rate then PCT-like measurements can be performed, which are comparable to "classical" PCT measurements as obtained by Sieverts' like setups. However, the entropy and enthalpy values found are somewhat lower as compared to values reported in literature.

Instead of performing an isothermal measurement, a certain temperature ramp can be given to the heat exchanger making it possible to perform temperature desorption experiment resembling TPD measurements.

Our measurements show that the determination of properties of bulk quantities of metal hydride storage materials can be done fast and quite accurate up to high pressures and temperatures at a broad range of flows. The possibility to measure and control all mass and heat flows to and from the reactor enables us to test newly developed materials under a large variety of conditions. By the use of a CompacGC, we will also be able to determine the influence of gas contaminations on the storage properties of the bed for $\mathrm{CO}, \mathrm{CO}_{2}, \mathrm{CH}_{4}, \mathrm{~N}_{2}$, and $\mathrm{O}_{2}$ in the range of 10-1000 ppm.

The hydrogenation experiments reported here also indicate challenges for solid state hydrogen storage systems. For example, one can aim at high filling rates, that is for onboard storage applications, however, two counteracting processes determine the effective hydrogenation of the reactor bed. First, a high feed flow is required, however, if this feed flow is higher than the uptake rate of the material, a pressure decrease (absorption by the bed material) will occur after the filling process is stopped, increasing the effective filling time. Second, a high filling rate causes, due to the exothermic reaction, a (local) increase of the bed temperature and thereby a lowering of the efficient storage capacity of the tank. Furthermore, at high filling rates the heat management of the tank becomes more and more challenging. Even with a heat exchanger with a high cooling capacity, local heating effects of the bed cannot be excluded.

Filling times below 4 min lead to a considerable amount of heat that needs to be removed from the storage system, see Fig. 15. Here it is shown that even with a modest amount of storage material, the local bed temperature increases (depending on the properties of the used material, set temperature, and feed flow). The maintaining of isothermal conditions is challenging although the heat exchanger should be able to control

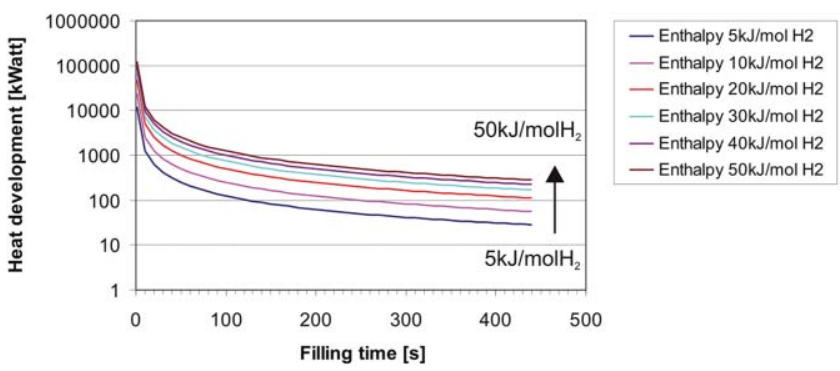

FIG. 15. (Color online) Heat development as a function of time for the storage of $5 \mathrm{~kg}$ of hydrogen at different enthalpy of formation values.

the temperature in the range of a few degrees for both hydrogen absorption and desorption.

The hydrogenation reactor presented here differs in many aspects from generally used characterization setups for metal hydride research. The broad range of different hydrogen storage materials requires a wide range of measurement conditions. Temperatures from room temperature up to $500^{\circ} \mathrm{C}$ in combination with pressures in the range from mbar to 100 bar are not uncommon, which requires a great flexibility of the characterization techniques. In general, these (classical) techniques use only a few mg up to $1 \mathrm{~g}$ of storage material examined under equilibrium conditions. The techniques most used for determining the hydrogen storage capacity are gravimetric based (TGA), volumetric based (Sieverts) and TPD. The errors made by using these techniques are generally related to the indirect nature of TGA and Sieverts and/or operating near the sensitivity limit of the equipment. For a high pressure TGA a typical accuracy for a $300 \mathrm{mg}$ sample at 1 bar is $\sim 10^{-4}$ wt. \%, while for a PCT Pro-2000, state-of-the-art Sieverts instrument for measuring the sorption properties, measurements can be made at pressures between 0.001 and 200 atm and at temperatures up to $400{ }^{\circ} \mathrm{C}$. This instrument has an estimated accuracy of $0.2 \mathrm{wt}$. \% for a $300 \mathrm{mg}$ sample measured at 101 bar. $^{39}$ For comparison, our storage reactor is able to operate in the temperature range from room temperature to $350{ }^{\circ} \mathrm{C}$ at pressures between a few mbar up to 75 bar with a storage bed between a few grams up to a few hundred grams. Although the reactor is designed to perform measurements at nonequilibrium conditions, it is possible to determine storage capacities with and error of 0.1 wt. $\%$, temperature desorption profiles (to be published), and enthalpy/entropy of formation values which are comparable with reported literature values. $^{40-44}$ Furthermore, this setup is a device to test storage materials under practical conditions (loading times, quantities, contaminations, and heat management) which are not possible with the previous mentioned techniques. From the diversity of materials and conditions, it is also clear that no single measurement technique will be appropriate for all of the materials that are currently being investigated for hydrogen storage. Therefore, our testing facility enables one to test storage samples under relevant conditions for possible applications by monitoring all heat and mass flows, however crosschecks by other techniques will provide the necessary reference data. Furthermore, by making a few modifications to the 
reactor section which regulates the hydrogen desorption process, the whole hydrogenation cycle can be controlled and investigated. In addition, once all components (values, flow controllers, etc.) are automated and are integrated in a controlprogram, a realistic driving cycle can be implemented. This will be part of further research and fine-tuning of the reactor setup.

In conclusion, we have developed a realistic downscaled hydrogen storage reactor which can be operated under conditions reflecting a day-to-day use, designed to study the main characteristics of the absorption process and the effects of the most important operating conditions. The absorption process is characterized by the exothermic hydrogenation reaction and consequently the absorption rate mainly depends on the successful heat and mass transport of the reactor. The heat exchanger and used feed flow are found to have a significant effect on the hydrogen absorption properties.

\section{ACKNOWLEDGMENTS}

The authors are grateful to G. de Jong, R. Wesseling, R. IJpelaan, R. de Moel, and B van Egmond for technical support. This work has been financed by the Dutch Ministry of Economic Affairs in the framework of a SenterNovem EOS-LT Grant No. (EOSLT06024).

${ }^{1}$ L. Schlapbach and A. Zuttel, Nature (London) 414, 353 (2001).

${ }^{2}$ See http://www.hydrogen.energy.gov.

${ }^{3}$ F. Askri, M. Ben Salah, A. Jemni, and S. Ben Nasrallah, Int. J. Hydrogen Energy 34, 897 (2009).

${ }^{4}$ T. M. Brown, J. Brouwer, G. S. Samuelsen, F. H. Holcomb, and J. King, Int. J. Hydrogen Energy 33, 5596 (2008).

${ }^{5}$ H. Dhaou, S. Mellouli, F. Askri, A. Jemni, and S. Ben Nasrallah, Int. J. Hydrogen Energy 32, 1922 (2007).

${ }^{6}$ H. Dhaou, A. Souahlia, S. Mellouli, F. Askri, A. Jemni, and S. Ben Nasrallah, Int. J. Hydrogen Energy 35, 1674 (2010).

${ }^{7}$ M. R. Gopal and S. S. Murthy, Int. J. Hydrogen Energy 17, 795 (1992).

${ }^{8}$ M. R. Gopal and S. S. Murthy, Int. J. Hydrogen Energy 20, 911 (1995).

${ }^{9}$ Y. Asakuma, S. Miyauchi, T. Yamamoto, H. Aoki, and T. Miura, Int. J. Hydrogen Energy 29, 209 (2004).

${ }^{10}$ A. Jemni and S. Ben Nasrallah, Int. J. Hydrogen Energy 20, 43 (1995).

${ }^{11}$ A. Jemni and S. Ben Nasrallah, Int. J. Hydrogen Energy 20, 881 (1995).

${ }^{12}$ U. Y. F. Shmalkov, V. I. Kolosov, V. V. Solovey, L. A. Kennedy, and S. A. Zelepongu, Int. J. Hydrogen Energy 23, 463 (1998).

${ }^{13}$ D. Mat and Y. Kolpan, Int. J. Hydrogen Energy 26, 957 (2001).

${ }^{14}$ K. Aldas, D. Mat, and Y. Koplan. Int. J. Hydrogen Energy 27, 1063 (2002).

${ }^{15}$ F. Askri, A. Jemni, and S. Ben Nasrallah, Int. J. Hydrogen Energy 29, 195 (2004).

${ }^{16}$ H. Choi and A. F. Mills, Int. J. Heat Mass Transfer 33, 1281 (1990).

${ }^{17}$ Y. Wang, X. C. Adroher, J. Chen, X. G. Yang, and T. Miller, J. Power Sources 194, 997 (2009).

${ }^{18}$ F. Askri, A. Jemni, and S. Ben Nasrallah, Int. J. Hydrogen Energy 20, 43 (1995).

${ }^{19}$ A. Demircan, M. Demiralp, Y. Kaplan, M. D. Mat, and T. N. Veziroglu, Int. J. Hydrogen Energy 30, 1437 (2005).

${ }^{20}$ K. Aldas, A. D. Mat, and Y. Kaplan, Int. J. Hydrogen Energy 27, 1049 (2002).

${ }^{21}$ D. Sun and S. Deng, Int. J. Hydrogen Energy 15, 807 (1990).
${ }^{22}$ D. Sun and S. Deng, J. Less-Common Met. 155, 217 (1989).

${ }^{23}$ M. Botzung, S. Chaudourne, O. Gillia, C. Perreet, M. Latroche, A. Percheron-Guegan, and P. Marty, Int. J. Hydrogen Energy 33, 98 (2008).

${ }^{24}$ M. R. Gopal and S. S. Murthy, Chem. Eng. Process. 32, 217 (1993).

${ }^{25}$ A. Jemni and S. Ben Nasrallah, Int. J. Hydrogen Energy 22, 67 (1997).

${ }^{26}$ T. Nakagawa, A. Inomata, H. Aoki, and T. Miura, Int. J. Hydrogen Energy 25, 339 (2000).

${ }^{27}$ B. MacDonald and A. Rowe, J. Power Sources 161, 346 (2006).

${ }^{28}$ U. Mayer, M. Groll, and W. Supper, J. Less-Common Met. 131, 235 (1987).

${ }^{29}$ A. Jemni, S. Ben Nasrallah, and J. Lamloumi, Int. J. Hydrogen Energy 24, 631 (1999).

${ }^{30}$ S. Suda, N. Kobayashi, K. Yoshida, Y. Ishido, and S. Ono, J. Less-Common Met. 74, 127 (1980).

${ }^{31}$ S. Suda, N. Kobayashi, and K. Yoshida, Int. J. Hydrogen Energy 6, 521 (1981).

${ }^{32}$ E. Suissa, I. Jacob, and Z. Hadri, J. Less-Common Met. 104, 287 (1984).

${ }^{33}$ A. Kempf and W. R. B. Martin, Int. J. Hydrogen Energy 11, 107 (1986).

${ }^{34}$ D. Sun and S. Deng, J. Less-Common Met. 160, 387 (1990).

${ }^{35}$ M. Pons and P. Dantzer, Int. J. Hydrogen Energy 10, 611 (1994).

${ }^{36}$ E. Hahne and J. Kallweit, Int. J. Hydrogen Energy 23, 107 (1998).

${ }^{37}$ D. Sun and S. Deng, Int. J. Hydrogen Energy 15, 331 (1990).

${ }^{38}$ M. Pons and P. Dantzer, J. Less-Common Met. 172, 1147 (1991).

${ }^{39}$ F. S. Yang, G. X. Wang, Z. X. Zhang, X. Y. Meng, and V. Rudolph, Int. J. Hydrogen Energy 35, 3832 (2010).

${ }^{40}$ Y. Kaplan, M. Ilbas, M. D. Mat, M. Demiralp, and T. N. Veziroglu, Int. J. Energy Res. 30, 447 (2006).

${ }^{41}$ V. Fuster, F. J. Castro, and G. Urretavizcaya, J. Alloys Compd. 446, 224 (2007).

${ }^{42}$ J. R. Ares, F. Cuevas, and A. Percheron-Guegan, J. Alloys Compd. 404, 327 (2005).

${ }^{43}$ H. M. Mendelsohn, D. M. Gru, and A. E. Dwight, Nature (London) 269, 45 (1977)

${ }^{44}$ S. K. Pandey, A. Srivastava, and O. N. Srivastava, Int. J. Hydrogen Energy 32, 2461 (2007).

${ }^{45}$ P. D. Goodell and P. S. Rudman, J. Less-Common Met. 89, 117 (1983).

${ }^{46} \mathrm{R}$. Griessen and T. Riesterer, Topics in Applied Physics: Hydrogen in Intermetallic Compounds I, edited by L. Schlapbach (Springer, Berlin, Heidelberg, 1988), Vol. 63, p. 219.

${ }^{47}$ R. Gremaud, "Hydrogenography: A thin film optical combinatorial study of hydrogen storage materials," Ph.D. dissertation (Amsterdam Vrije Universiteit, 2008).

${ }^{48}$ A. S. Tetelman and W. D. Robertson, Metall. Trans. AIME 224, 775 (1962).

${ }^{49}$ N. J. Petch and P. Stables, Nature (London) 169, 842 (1952).

${ }^{50}$ W. J. Barnett and A. R. Troiano, Metall. Trans. AIME 209, 486 (1957).

${ }^{51}$ J. K. Tien, A. W. Thompson, I. M. Bernstein, and R. J. Richards, Metall. Trans. A 7, 821 (1976).

${ }^{52} \mathrm{P}$. Bastien and P. Azou, in Proceedings of the World Metallurgy Congress (First American Society of Metals, 1951), p. 535.

${ }^{53}$ A. N. Stroh, Adv. Phys. 6, 418 (1957).

${ }^{54}$ C. D. Beachem, Metall. Trans. 3, 437 (1972).

${ }^{55}$ D. S. Shih, I. M. Robertson, and H. K. Birnbaum, Acta Metall. 36, 111 (1988).

${ }^{56}$ D. G. Westlake, Trans. ASME 62, 1000 (1969).

${ }^{57} \mathrm{H}$. K. Birnbaum, The Minerals (Metals and Materials Society, Warrendale, 1990), p. 639.

${ }^{58}$ E. S. Kikkinides, M. C. Georgiadis, and A. K. Stubos, Energy 31, 2428 (2006).

${ }^{59}$ D. Ohlendorf and H. E. Flotow, J. Less-Common Met. 73, 25 (1980).

${ }^{60}$ A. L. Shilov, M. E. Kost, and N. T. Kuznetsov, J. Less-Common Met. 144, 23 (1988).

${ }^{61}$ J. J Murray, M. L Post, and J. B Taylor, J. Less-Common Met. 80, 211 (1981).

${ }^{62}$ J. T. Koh, A. J. Goudy, P. Huang, and G. Zhou, J. Less-Common Met. 153, 89 (1989). 